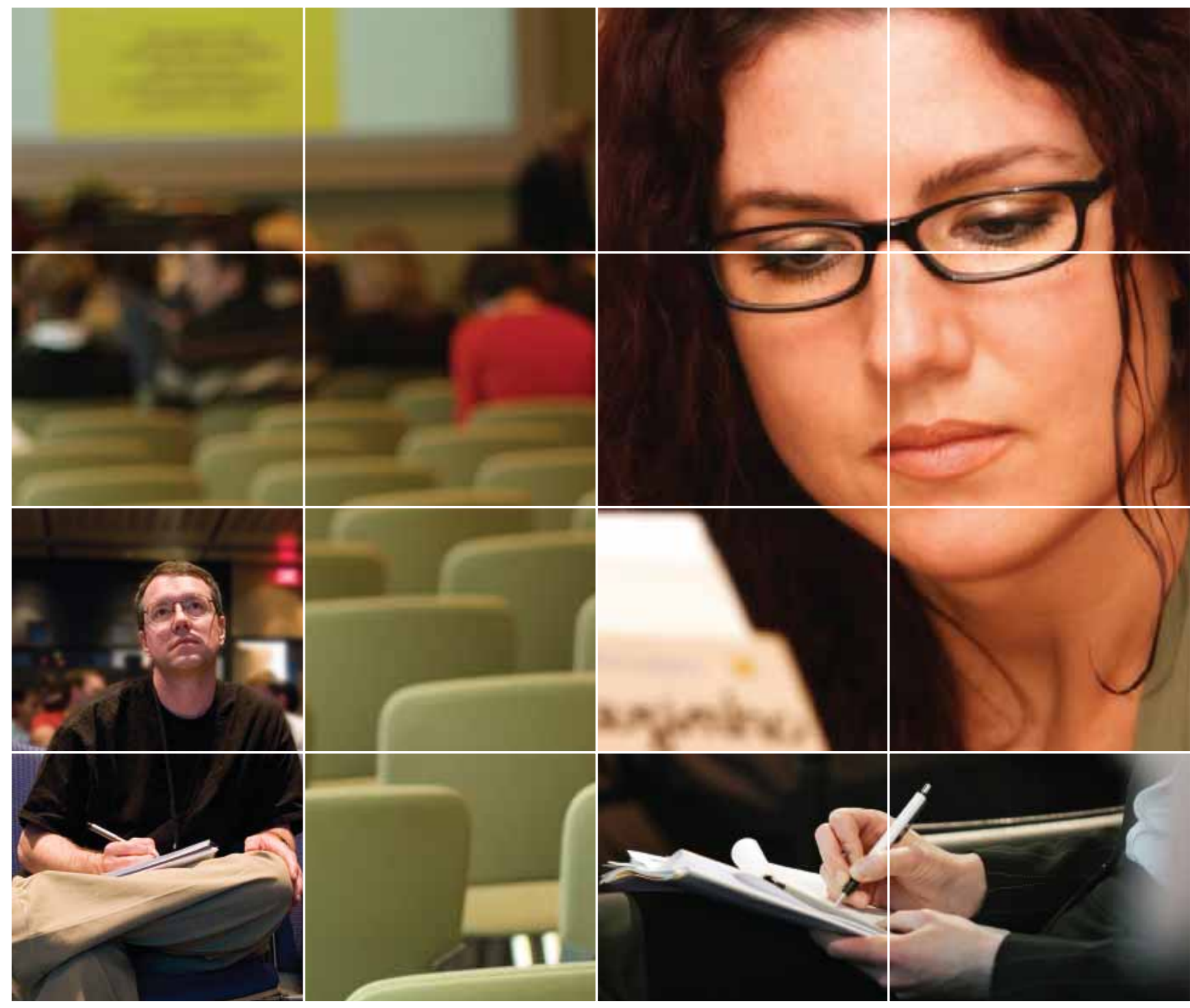

\title{
CONTINUING EDUCATION PROGRAM
}

The Canadian Association of Optometrists and the local organizing committee are pleased to provide world class continuing education. A total of 15 hours will be offered for Optometrists and 12 hours for Optometric Assistants.

Hours will be electronically monitored, tabulated and forwarded to you following the Congress.

We guarantee something of interest for everyone. You will have the opportunity to experience both local, national and international speakers. The lectures will be conducted in the recently completed state of the art TCU Place and Convention Centre, which is located opposite the Hilton Garden Inn. The TCU facility hosts the newest audio visual technological equipment and all the comforts of home. For those not staying at the Hilton, a shuttle service will travel between TCU Place and the Sheraton Cavalier and Bessborough Hotels for your daily convenience. 


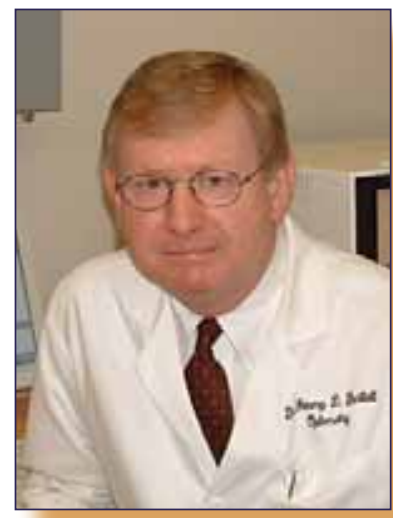

Contemporary Treatment Strategies for Primary Care Optometry

Thursday, July 19: 8:15 am -10:30 am

This course considers important clinical tips and pearls regarding the use of both topical and oral medications in optometry. Topics include ophthalmic sprays for children and adults, a new diagnostic test for Horner's syndrome, use of medications in pediatrics and during pregnancy, selection of and prescription writing for controlled substances, prevention of drug interactions, and many others. Emphasis is placed on utilization of new information that has practical value for treating day-to-day patients.

\section{New Treatment Strategies for Dry Eye and Ocular Infections}

Thursday, July 19: 1:00 pm - 3:00 pm

This course considers new concepts and new medications for treating patients with dry eye, an extremely common condition affecting every optometrist's patients. Novel therapeutic procedures and new delivery devices are discussed including nutritional agents that have recently been shown to have value in treating patients with moderate to severe dry eye syndrome. New medications to treat ocular infection are discussed in some detail, with an explanation of how these newer drugs may have advantages over existing therapies. Emphasis is placed on drugs and procedures that have practical value in primary care optometric practice.

Jimmy D. Bartlett, O.D. received his Doctor of Optometry degree in 1974 from Southern College of Optometry. After serving as Chief of the Optometry Service at the Tampa V.A Hospital and Assistant Professor in the Department of Ophthalmology of the University of South Florida College of Medicine, he assumed his present position at the School of Optometry, University of Alabama at Birmingham in 1977. Dr Bartlett is currently Chairman of the Department of Optometry, Professor of Optometry in the School of Optometry and Professor of Pharmacology in the Department of Pharmacology and Toxicology at the University of Alabama School of Medicine.

Dr Bartlett has served as Editor-in-Chief of the Journal of the American Optometric Association, Co-editor of Clinical Ocular Pharmacology, and he serves on the editorial advisory board for Ophthalmic Drug Facts and Journal of Ocular Pharmacology and Therapeutics.

Dr. Bartlett has delivered more than 1,000 lectures throughout the world to both clinical and research audiences, and he is the recipient of two honorary degrees. In 2000 he was selected by Review of Optometry as one of the most influential Optometrists of the $20^{\text {th }}$ Century.

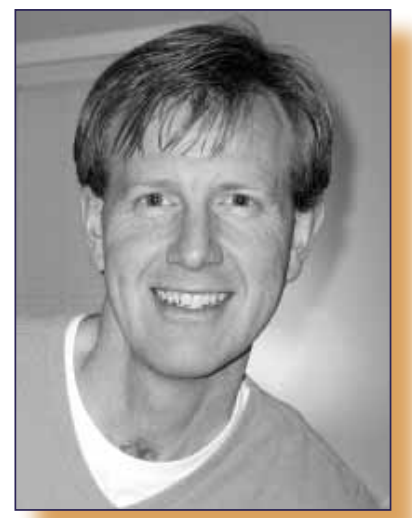

\section{Retina 2007}

Thursday, July 19: 10:30 am - 12:00 pm

\section{Past, Present and Future of Medical and Surgical Retina}

Thursday, July 19: 3:15 pm - 4:15 pm

A comprehensive review of current retinal therapies and surgeries. Dr Erasmus will attempt to cover all areas of interest and recent progress, referencing historical development, current thinking and future directions.

Murray J Erasmus MD, FRCSC received his undergraduate medical degree from the University of Cape Town in South Africa in 1983, and moved to Canada in 1985. He spent two years in general practice in rural Saskatchewan before starting a residency in Pediatrics at the University of Saskatchewan. After two years of Pediatric training he changed career direction and completed a residency in Ophthalmology at the University of Saskatchewan. This was followed by medical 
and surgical vitreo-retinal fellowship training at the University of Toronto in 1991-1992. In 1992 Dr Erasmus then returned to join the Department of Ophthalmology at the University of Saskatchewan as Assistant Clinical Professor. He has been actively involved in the residency training program in Ophthalmology at the $\mathrm{U}$ of $\mathrm{S}$, and served as Director of the Ophthalmology Residency Training Program from 1998 to 2001. He has been active in many University and Departmental Committees. Dr Erasmus has chaired several national surgical retina meetings, and has been a panelist and speaker at numerous medical and surgical retina conferences. He has been a Principal Investigator in several international clinical trials and maintains a keen research interest, particularly in the area of age related macular degeneration, and he also sits on the advisory board for several pharmaceutical companies. Dr Erasmus and his family recently left the prairies and relocated to Victoria BC in 2003. He is currently an Assistant Clinical Professor with the Department at the University of British Columbia, and is also involved in the Island Medical Program with the University of Victoria. He has a busy private vietreo-retinal practice in Victoria.

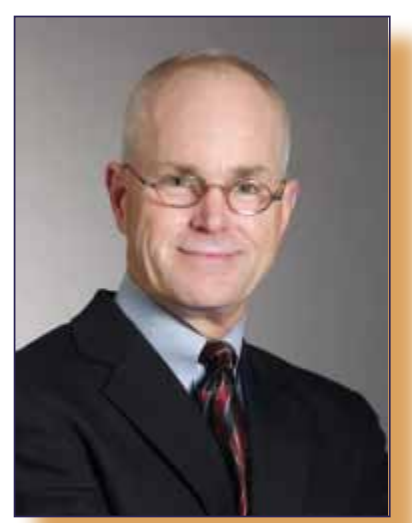

\section{Dry Eye Treatment \& M anagement: What you M ay Be M issing}

Saturday, July 21: 8:15 am - 10:15 am

Significant numbers of patients in primary care offices complain of or exhibit clinically significant dry eye. Recent studies confirm that patients expect relief from dry eye symptoms in the form a solid treatment plan. Patients are leaving offices due to indifference of the professional toward their dryness issues. This course evaluates the pathophysiology of dry eye and sorts out the latest in diagnostic technology. The full compliment of treatment modalities is covered with an emphasis on new technology and what really solves your patient's complaints and concerns. Anti-inflammatory treatments will be extensively covered along with the real word on nutritional supplements. Punctal occlusion is changing with new intracanalicular plugs, which can simplify the insertion process and ensure the dislodging/loss are kept to a minimum. We close with a practical look at the finances of the dry eye patient and ensure that you know what you may be missing. Practices are specializing in this area and finding great success at developing a strong patient loyalty.

\section{It's Not Just Cataract Surgery Anymore!}

Saturday, July 21: 10:30 am - 12:00 pm

Technology is rapidly expanding and providing new options to achieve optimal outcomes for our patients. Cataract surgical procedures have changed dramatically over the past twenty-years leading to the realization that these are truly refractive procedures with highly predicable endpoints. Learn the latest in cataract care and the options that you should expect when you guide a patient though this process, make the referral and provide the pre and post-operative care. New and exciting IOL options include astigmatism correction, multifocal/accommodative and aberration reducing implants to provide improved functional vision and satisfaction. This seminar promises to arm you with the latest cataract care and management technology that you can use to gain higher levels of patient satisfaction.

John W. Lahr, OD, FAAO is based in Minneapolis, Minnesota and has served in a number of leadership positions in the American Optometric Association and has served as a member of the Clinical Practice Guidelines Committee to develop practice standards for optometry. He was the AOA's first representative to the American Medical Association's CPT coding Health Care Professional's Advisory Committee. He is a well known lecturer nationally and internationally. Dr. Lahr is an Editorial Board member for Optometric Management and currently serves as the Director of Primary Eye Services for STAAR Surgical, Inc. and Director for Professional Services for EyeMed Vision Care.

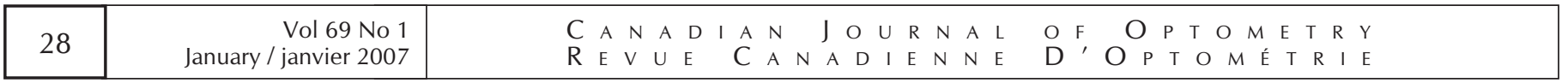




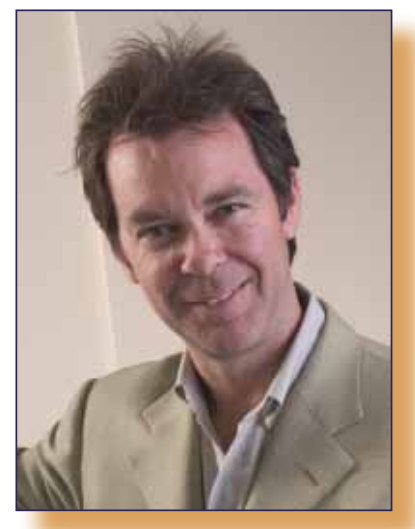

Just Hype or the Holy Grail? Wavefront-guided LASIK

Thursday, July 19: 1:00 pm - 3:00 pm

With the advent of wavefront-guided LASIK, there was the expectation that we would be seeing many people with $20 / 10$, or so called super vision. While this has not been the case, there are some definite advantages to the wavefront-guided technique, and these will be discussed. In addition, current limitations to wavefront-guided treatments will be discussed, and new developments in the near future that we can expect to see will also be mentioned. (one hour)

\section{Careful With That Thing Or You'll Lose An Eye! LASIK Complications} Thursday, July 19: 1:00 pm - 3:00 pm

While LASIK has been extremely well received by many individuals, it doesn't take long when searching the internet to find many dissatisfied patients, who have unfortunately, experienced some of LASIK's complications. In this lecture, we will discuss the common and rare complications of LASIK, both with the microkeratome and Intralase, and will discuss their frequency, as well as their treatment and expected outcomes. We will also put LASIK complications in context, by comparing them with the complications of contact lens wear.(one hour)

Dr. James H. Underhill received his medical degree from the University of Saskatchewan and his ophthalmology training at Queen's University in Ontario. He subsequently performed a corneal surgery subspecialty fellowship at the University of British Columbia in Vancouver, and holds a fellowship from The Royal College of Physicians and Surgeons of Canada. He is also a Fellow of the American Academy of Ophthalmology and the American Society of Cataract and Refractive Surgeons. He has a particular interest in refractive, corneal and cataract surgery, and has been in practice in Saskatoon since 1989. He has presented papers at meetings in Australia, Italy, Spain and throughout North America.

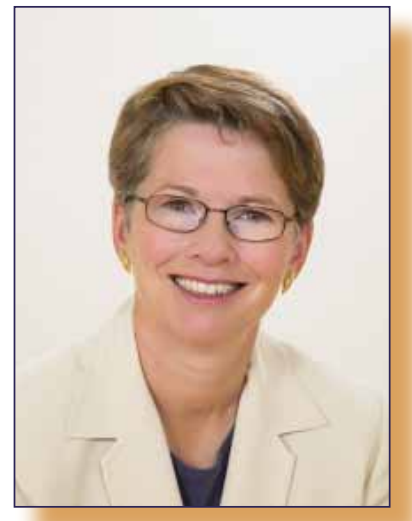

\section{Appreciative Teamw ork (Joint, ODs \& Optometric Assistants)}

Thursday, July 19: 10:30 am - 12:00 pm

Appreciative Inquiry is a process that offers a positive, strengths-based approach to organization development. Appreciative Teamwork starts with the premise that aligned teams are more powerful than individuals working alone. This workshop will coach participants to create a team vision of success and a written plan to make it happen. Participants will be challenged to think, to dream, and to create a written plan of what they really, really, really, really want. What does the ideal future look like? What is working right now? What are the collective strengths of the practice? What challenges exist? What opportunities exist? What resources are available? Who needs to do what by when? Participants will leave with their own appreciative teamwork action plan.

Cheryl Dougan has diverse experience working with entrepreneurs, including coaching workshops in Dallas and Los Angeles. Recent engagements have included the Canadian Leadership Conference, the Credit Institute of Canada (Saskatchewan Chapter), the University of Saskatchewan (Business and Leadership Program, Effective Executive Program), the Instrumentation Systems and Automation Society (ISA), the Urban Municipal Administrators Association of Saskatchewan, Canadian Society of Club Managers, Alberta Rural Extension Services, Women Entrepreneurs of Saskatchewan, and Community Futures. As a coach, Cheryl's goal is to connect her audience to their own wisdom. She has been described as a "community booster", "professional optimist", and, given her witty and entertaining style, a "toddler with no fear". 


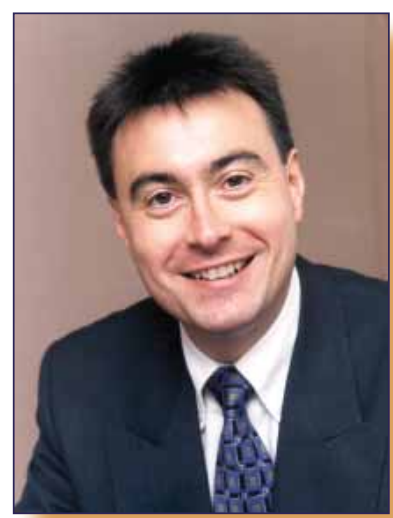

\section{Contact Lens Solutions Overview}

Thursday, July 19: 3:15 pm - 4:15 pm

This lecture will review the development of modern care systems, describe in detail their compositional differences and review how clinicians can maximise the performance of these systems to obtain the best clinical results with their patients. Course Objectives include: to understand the differences in deposition patterns that exist between conventional and silicone hydrogel lens materials; to understand the differences in composition between modern care regimens; to understand the potential for abnormal corneal staining patterns that occur when various combinations of lens materials and care regimens are used; and to better understand the importance of selecting an appropriate care regimen to improve subjective lens performance.

\section{If you Want to Win, You've Got to Stay in the Game}

presented by Dr L. Jones and Dr Keir (see Dr Keir's biography below)

Saturday, July 21: 10:30 am - 12:00 pm

As a result of the rapidly expanding demand worldwide for silicone hydrogel contact lenses, many new lenses and designs incorporating these revolutionary materials are being developed and marketed. This interactive presentation will provide the latest information on the clinical performance of this new generation of contact lenses in an imaginative and engaging format. The audience will be able to take part in a "game" in which a series of conditions and cases related to silicone hydrogels will be discussed. Interactive keypads will be employed allowing instantaneous feedback from participants. This entertaining approach is certain to add value and relevance to this topic and to enhance the overall learning experience.

Dr Lyndon Jones is a Professor at the School of Optometry and Associate Director of the Centre for Contact Lens Research at the University of Waterloo (UW), where he is responsible for teaching contact lenses and anterior segment disease management. He is also cross-appointed to the Departments of Physics, Biology, Chemistry and Chemical Engineering at UW and an Adjunct Professor in the Chemical Engineering Department at McMaster. He graduated in Optometry from the University of Wales, UK in 1985 and gained his PhD from the Biomaterials Research Unit at Aston University, UK in 1998. He holds three of the higher awards granted by the British College of Optometrists, is a Fellow of the American Academy of Optometry, in which he is a Diplomate in Cornea and Contact Lenses, and is also a Fellow of the International Association of Contact Lens Educators. He is a former partner in a three-times award winning private practice in London and has been the recipient of numerous awards, including the 2005 UW's "Distinguished Teacher Award", and 2002 BCLA "Irving Fatt Memorial Lecture".

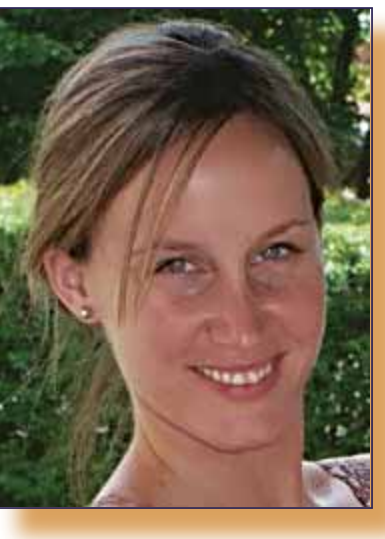

If you Want to W in, You've Got to Stay in the Game

presented by Dr L. Jones and Dr Keir (see lecture description above)

Saturday, July 21: 10:30 am - 12:00 pm

Nancy Keir, BSc, OD is currently a Clinical Scientist at the Centre for Contact Lens Research at the University of Waterloo in Ontario, Canada, where she is responsible for conducting clinical research in the areas of contact lenses and refractive surgery. She graduated with honours in Optometry from the University of Waterloo and is currently working towards her PhD Degree in Vision Science. Nancy also works as an associate optometrist in Waterloo on a part-time basis. 


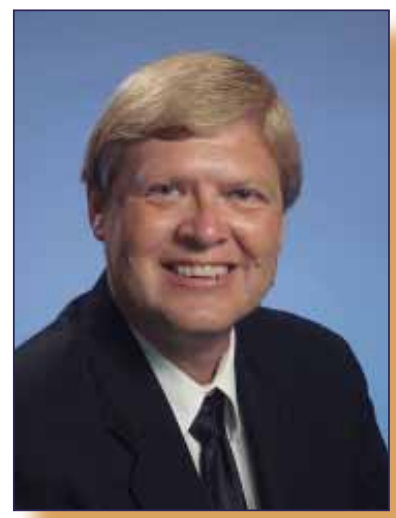

99 M arketing Techniques for Your Practice (JOINT)

Friday, July 20: 8:15 am - 10:15 am

Motivating and Retaining Staff

Friday, July 20: 10:30 am - 11:30 am

This course provides tools for the learner to use in retaining employees. Statistics are presented showing the need for keeping employees happy. Management theory, motivation tactics and a plan for keeping employees are applied to a case study and exercise. The audience will share ideas for motivating and retaining staff. Upon completion, the learner should be able to determine what motivates their employees, list strategies to use in retaining employees, and develop management plans for keeping employees happy.

Peter G. Shaw -McMinn, OD is a 1978 graduate of the Southern California College of Optometry where he is presently an Assistant Professor responsible for coordinating and teaching the practice management courses. He is currently the chairman of the ASCO special interest group, the Association of Practice Management Educators and the AOA Practice Management Committee. He is a member of the AOA Membership Services Executive Committee, the AOA Practice Management University Task Force, and serves on the Board of Directors of the Vision West Inc. Buying group. He is one of three optometrists appointed to the Better Vision Institute's Advisory Committee. He is the senior partner of Sun City Vision Center, a group practice including four optometrists and one ophthalmologist in Riverside County, California. He writes and lectures extensively on practice management topics. Dr. Shaw-McMinn is a consulting editor to the AOA News Practice Strategies.

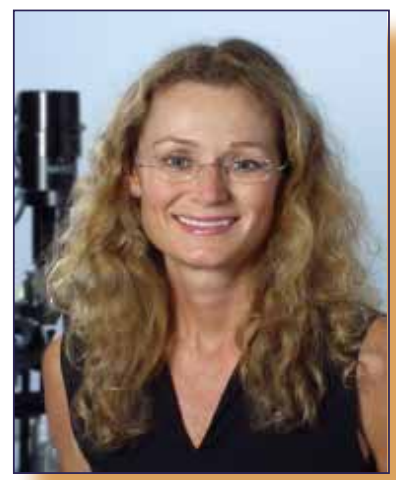

\section{Prescribing Prism for Strabismus - Everything You Wanted to Know But Were Afraid to Ask Friday, July 20: 8:15 am - 10:15 am}

Clinical guidelines for vertical and horizontal strabismus, for comitant and noncomitant deviations, and for functional and cosmetic purposes are presented and illustrated using case reports. Implementation of prism is included.

\section{Differential Diagnosis of Headaches in Children}

Friday, July 21: 10:30 am - 11:30 am Presents a strategy for the differential diagnosis of headaches in children with special emphasis on differentiating between visually-related, migraine, tension, \& organic headaches.

Susan Cotter OD, MS is a pediatric optometrist who received her OD from the Illinois College of Optometry and completed a residency in Children's Vision at the Southern California College of Optometry (SCCO). Currently, she is a Professor at the Southern California College of Optometry and a Research Professor in the Department of Ophthalmology at the University of Southern California's Keck School of Medicine. Dr Cotter is a Diplomate and a past Chair of the American Academy of Optometry's Binocular Vision, Perception, \& Pediatric Optometry Section. She is a member of the Executive Committee of the Pediatric Eye Disease Investigator Group and serves on the American Optometric Association's Council on Research. Dr Cotter is a recipient of the American Optometric Foundation's Ezell Fellowship and editor of the textbook, Clinical Applications of Prisms. At present, Dr Cotter is an investigator for several studies funded by the National Eye Institute. She is Vice Chair and the SCCO principal investigator for the Convergence Insufficiency Treatment Trial, SCCO principal investigator for the Collaborative Longitudinal Evaluation of Ethnicity and Refractive Error and the Amblyopia Treatment Studies (ATS), and co-principal investigator for the Multi-Ethnic Pediatric Eye Disease study at USC. 


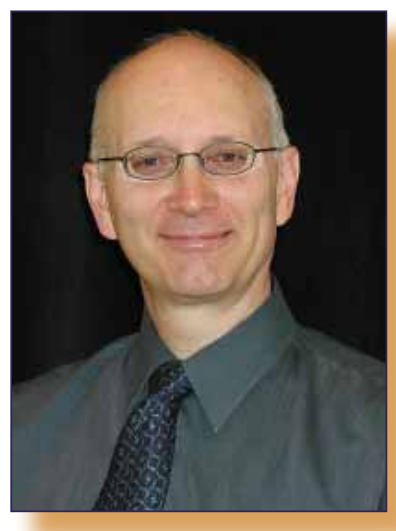

Be a '10' in Serving EXTRA-Ordinary Patients

Thursday, July 19: 1:00 pm - 2:30 pm

Every day, optometric offices have patients that present with problems and conditions that are NOT routine, that are 'out of the ordinary'. Whether they be partially sighted, physically challenged, chronically late, specialty contact lenses, acute conjunctivitis or refractive surgery candidate, is your office prepared for those EXTRA-ordinary patients? Follow these patients through the office from their first telephone contact, to their arrival at Reception, on to ancillary testing and in to the dispensary. Be a '10' at serving the EXTRA-ordinary patient'!

Dr. R Myles McMorris is a member of the Board of Directors and Chair of the Planning Committce of the Saskatchewan Division of the Canadian National Institute for the Blind (CNIB). He was the founder of the SAO's Official Web-Site and Web-Master for 5 years. He was Editor of the SAO's Official Newsletter for 5 years. He is proud to have received the SAO's 'Optometrist of the Year' Award in 2000. He is on the Board of Directors of the renowned 'Temple Gardens Mineral Spa and Resort Hotel'. Dr McMorris is a partner in Primary Eye Care which was founded by Dr Myles McMorris and Dr. Jacqueline John in 1982.

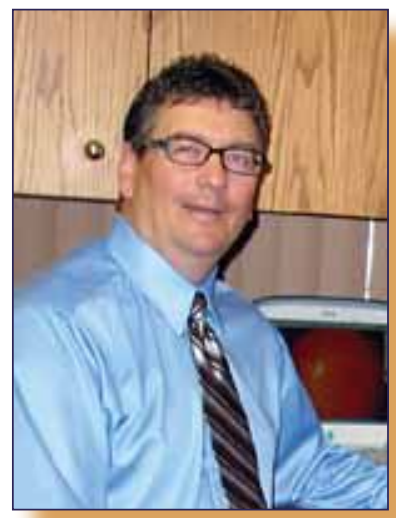

\section{What Every Parent Should Know About Their Children's Vision Before They Leave Your Office \\ Friday, July 20: 10:30 am - 11:30 am}

The presentation will address demystifying the optometric eye examination and effectively communicating the benefits of optometric care to the parents of young patients. Dr Ross will include a summary of current optometric thinking on refractive, eye alignment, eye movement and visual processing disorders and their potential effects on children. A summary of key messages for parents as well as methods and styles of effectively communicating these messages will be presented. A lighthearted look at how to interact with our most honest patients will be the central theme.

Dr Jim Ross graduated from the University of Waterloo School of Optometry in 1978. Dr Ross has served on many professional and clinical committees of the Saskatchewan Association of Optometrists and is a past president and past registrar of the Saskatchewan Association of Optometrists. Dr Ross is one of five optometrists who practice at Cityview Optometry in Regina. He frequently provides vision care services to children who have been identified as having a vision problem that may interfere with their academic performance. Dr Ross lives in Regina with his wife Brenda and their two university age children. He is an active golfer, squash player and photographer.

\section{Appreciative Teamwork (JOINT)}

Thursday, July 19: 10:30 am - 12:00 pm

Presented by Cheryl Dougan. See page 29

\section{$99 \mathrm{M}$ arketing Techniques for Your Practice (JOINT)}

Friday, July 20: 8:15 am - 10:15 am

Presented by Peter G. Shaw-McMinn, OD. See page 31 


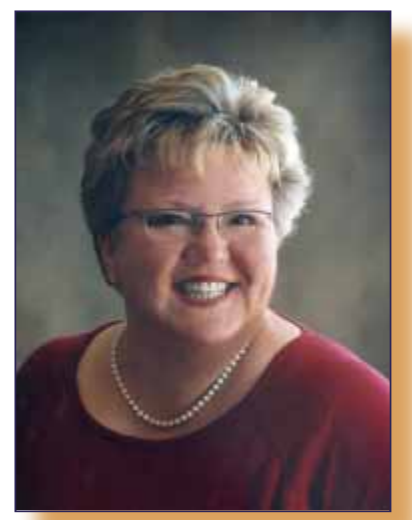

\section{Words, Words, Words}

Thursday, July 19: 3:15 pm - 4:15 pm

Confused about the terminology that the Optometrist uses on files, and especially in those letters you have to type? Dr. Hansen will enlighten all as to what many of these terms mean and how to spell them.

Dr Joan Hansen an optometrist in private practice in Tsawwassen, British Columbia, was elected President, Canadian Association of Optometrists effective July 1, 2004. Serving Tsawwassen for 21 years, Dr Hansen is active in service to optometry at a provincial and national level. She served as a Board member, BC Association of Optometrists, from 1984 to present and has held various positions. She was active in public relations work, serving as a media spokesperson for the BCAO and hosted a weekly open line radio show in Vancouver. She served as President, BCAO (1995 - 1997) and was appointed BCAO Councillor to CAO in 1997. She also served the BC Board of Examiners in Optometry, including as its Discipline Chair. Dr Hansen, originally from Manitoba, earned her Doctor of Optometry from the School of Optometry, University of Waterloo, 1979.

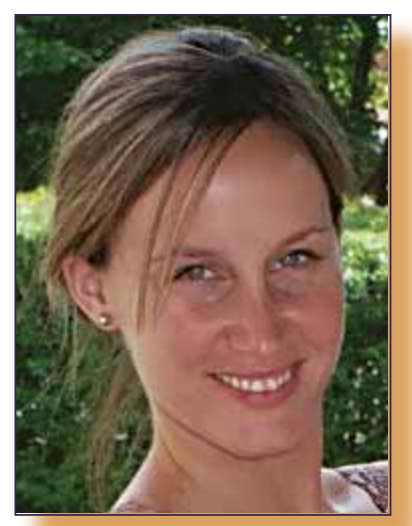

\section{Back-to-School: Don't Forget you Contact Lenses}

Saturday, July 21: 8:15 am - 10:15 am

Increasing numbers of tweens ( 8 to 12 years) and teens are wearing contact lenses. Very often these patients have diverse expectations and demands for their visual correction and eye care practitioners must offer them the widest possible choices for their individual personalities and needs. This lecture will explore the most appropriate contact lens options for this group of patients including daily disposables, silicone hydrogels and cosmetic tinted lenses. A practical approach to the prescribing, evaluation and management of contact lenses for tweens and teens will be given.

Nancy Keir, BSc, OD is currently a Clinical Scientist at the Centre for Contact Lens Research at the University of Waterloo in Ontario, Canada, where she is responsible for conducting clinical research in the areas of contact lenses and refractive surgery. She graduated with honours in Optometry from the University of Waterloo and is currently working towards her PhD Degree in Vision Science. Nancy also works as an associate optometrist in Waterloo on a part-time basis.

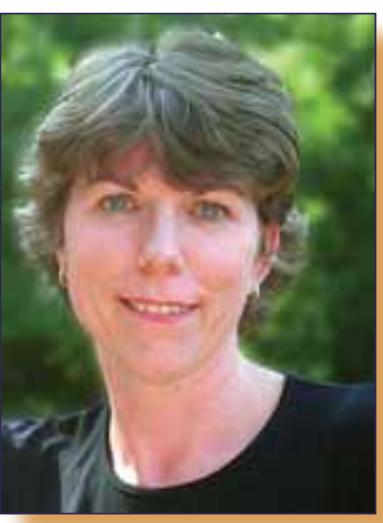

\section{Paediatric Vision}

Saturday, July 21: 10:30 am - 11:30 am

This course for optometric staff will cover the development of vision, risk factors for normal development, methods of examining infants and pre-school children and common ocular presentations and complaints. The aim of the course is to help optometric staff triage the pediatric patient and encourage a better understanding of the ocular abnormalities faced by this section of the population.

Deborah Jones BSc FCOptom DipCLP FAAO is currently the Clinic Director and head of the Paediatrics \& Special Needs Clinic in the School of Optometry at the University of Waterloo, Ontario, Canada. Debbie graduated in Optometry in 
1986 from City University in London, she became a member of the British College of optometrists in 1987 and attained Fellowship of the British College of Optometrists in 1992. She completed her Diplomate in Contact Lens Practice in 1993 and became a Fellow of the American Academy of Optometry in 1995.

She is formerly a partner in an award-winning private practice in London, has published articles in optometric journals, presented posters at conferences in Europe and North America and has presented at Canadian Optometric Continuing Education meetings. She is a past Clinical Tutor in binocular vision and contact lenses at the Institute of Optometry in London, a former Clinical Research Co-ordinator for Bausch \& Lomb in the UK and is a recipient of one of the first Canadian Foundation for Innovation (CFI) grants awarded to new faculty in Canada.

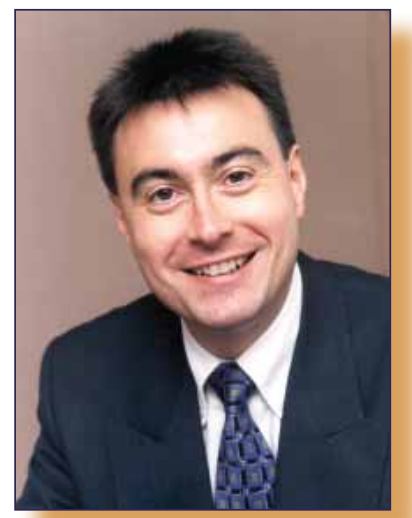

\section{Ocular Emergencies}

Thursday, July 19: 8:15 pm - 10:15 pm

Optometric staff are the first point of contact for patients telephoning the clinical practice. Patients present with symptoms which they believe to be of an urgent nature. The aim of this course is to provide information on appropriate triaging of patients to decide if their "ocular emergency" is indeed an emergency. Examples of common presentations will be presented and management decided upon in an interactive quiz format. Learning objectives include: how to triage a patient presenting with an ocular emergency - the appropriate questions to ask; how to decide if an apparent ocular emergency really does need emergency care; and identification of some of the more common ocular emergencies. (1 hour)

What's New \& Sexy in Contact Lenses Thursday, July 19: 8:15 pm - 10:15 pm

This course will review the latest trends and developments in contact lens materials, care systems and designs and update delegates on how best to use these technologies to better serve their patient's needs. (1 hour)

Dr Lyndon Jones is a Professor at the School of Optometry and Associate Director of the Centre for Contact Lens Research at the University of Waterloo. His research interests primarily focus on the interaction of novel and existing contact lens materials with the ocular environment and he has given over 300 invited lectures worldwide.

-

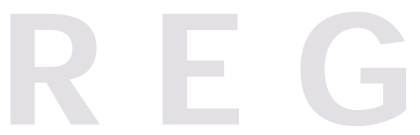
issue of the CJO. Once completed, please fax to (613)235-2025.

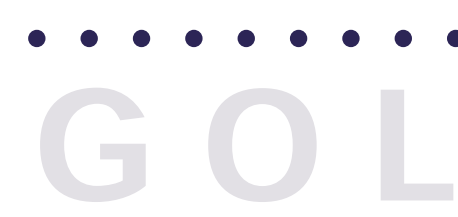

Those interested in the CAO President's Cup Golf Tournament, please refer to the separate Golf Registration form enclosed.

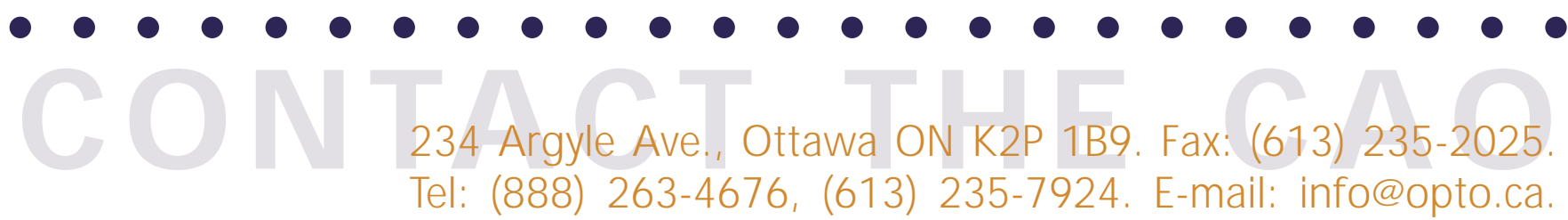

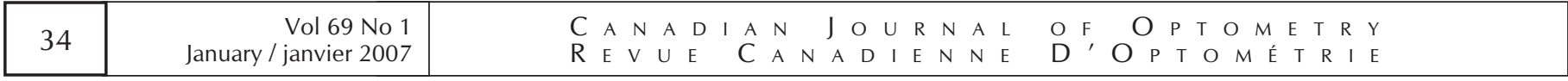


ORGANISED PRECONGRESS TOURS Golf trip to

\section{Waskesui}

The trip begins in Saskatoon at Dakota Dunes

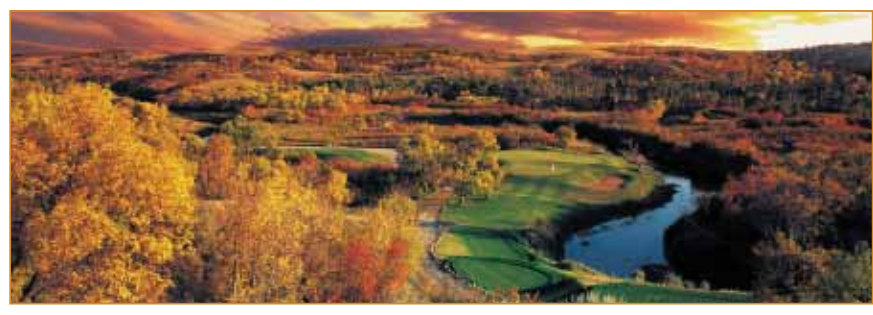

ON YOUR OWN

Ideas for Pre \& Post Congress Activities

Whatever your interests are, Saskatchewan is sure to provide you with unique on Saturday, and Riverside GCC on Sunday. The group travels next to Waskesui to play outstanding courses on Monday and Tuesday. Those that sign up for the tour will return in time for the President's Cup at the Willows on Wednesday morning. Space is limited so call early. Contact Dr Bob Gulka c/o the SAO atsao@sasktel.net.

\section{Northern fishing experience}

Dr Russ Schultz is coordinating the Pre-Congress fishing expedition to Jan Lake Lodge. Space is limited so please call early to reserve a spot. You will need to arrive in Saskatoon on Saturday or Sunday for the short drive up to Jan Lake. Contact Russ for details c/o the SAO office atsao@sask.tel.net.

\section{Spa Luxury, Pre-Congress Package}

For those of you that want to escape, relax and enjoy a luxury spa experience, you'll want to register for the Pre-Congress Spa package. You will be transported on Monday to the heart of downtown Moose Jaw where the exquisitely designed and luxurious Temple Gardens and Mineral Spa resort hotel is located (see mmw.templegardens. $s k . c a$ ). It captures the spirit, history, and charm of Western Canadian hospitality and features one of Canada's largest natural geo-thermal mineral water pools.

The rejuvenating, mineral-rich, geo-thermal waters are drawn from porous rock more than 1,350 meters below the earth's surface. The pool is situated on the top floor of the Spa Resort, adding "tree top" views of beautiful Crescent Park from the outdoor section of the pool.

To register and for details about any of the activities listed above, please contact The Saskatchewan Association of Optometrists at (306)652-2069orsao@sasktel.net.

Please note that all costs for the Pre-Congress tours are on a cost recovery basis and individuals are responsible for their own charges. opportunities and warm memories. Whether on your own, with family, friends and/or colleagues, following are some ideas to assist you in planning your trip to Canada's golden core.

You may not know that Saskatchewan offers some of the most spectacular camping locations in Canada. Services are available for you to organize your camping experience by renting a trailer, a cabin by the lake or catching a ride on one of many tour buses.

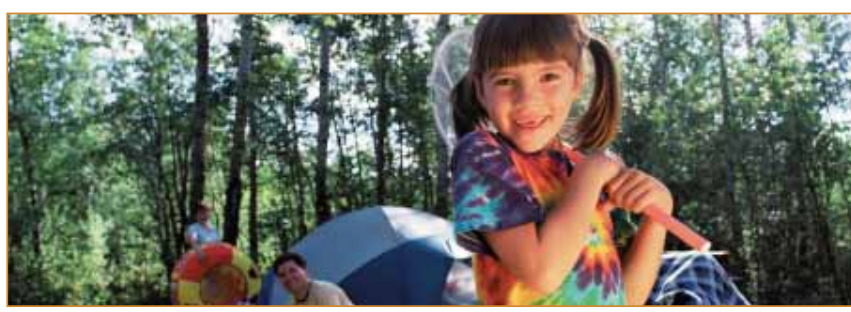

You may also want to consider adding Jan Lake Lodge to your itinerary. It offers activities the whole family can enjoy including fishing, bird watching, berry picking, basketball, horseshoes, nature trails, fire pits, beach and playground equipment, canoes and golf. Visit www. janlakelodge.com. For other destinations in Northern Saskatchewan visit www.northern.sask.info.

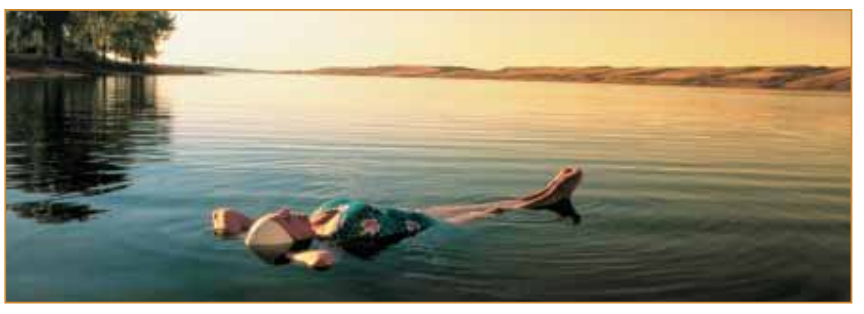

With over 250 golf courses, a Saskatchewan Golf Tour is definitely worth considering. You won't want to miss the opportunity to golf at some of the finest courses in Canada! Visit www.saskgolfer.com to find out more.

For more ideas for what there is to see and do in Saskatchewan, visit Tourism Saskatchewan at wmm.sask.tourism.com, or Tourism Saskatoon at wwm. tourismsaskatoon.com. See Canada, See Saskatoon Shine!

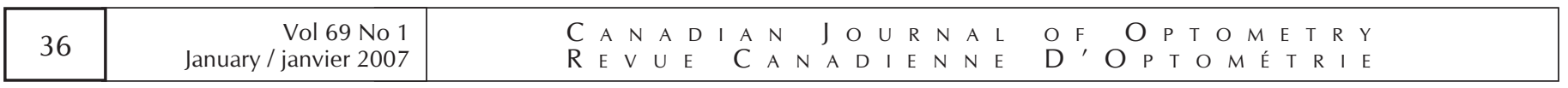

